\title{
ANÁLISE DE DADOS DE ECOSSONDAGEM DE FUNDO ORIUNDOS DE CRUZEIROS REALIZADOS ENTRE FORTALEZA (CE) E CHUÍ (RS) COM ENFOQUE NA MORFOLOGIA E TIPOS DE FUNDO
}

\author{
Caroline Vieira Cooke ${ }^{1}$, Lauro Saint Pastous Madureira², \\ Gilberto Henrique Griep ${ }^{3}$ e Marcelo Peres de Pinho ${ }^{4}$ \\ Recebido em 8 agosto, 2007 / Aceito em 12 dezembro, 2007 \\ Received on August 8, 2007 / Accepted on December 12, 2007
}

\begin{abstract}
Sea floor echosounding data obtained during seven scientific surveys were stored in the hydroacoustical database at the FURG Fishery Technology and Hydroacoustics Laboratory, for validation, analysis and interpretation. Data were collected by means of scientific echosounders operating at $38 \mathrm{kHz}$, along the Brazilian coast extending for 14.901 nautical miles (27.597 km), over the continental shelf, shelf break and adjacent area, between Fortaleza (CE) and Chuí (RS), Brazil. Visual analysis of the echograms allowed classification of bottom relief echotypes, and 80 echogram images were selected. Also, a total of 104 bathymetrical profiles were drawn from transects perpendicular to the coast. For the three first surveys $(9.695 \mathrm{mn})$, carried out along the southeastern and south coast, software for digital storage of the echograms was not available. For these surveys all bathymetric and bottom reflectivity ping to ping data were re-processed and 137 digital "bottom backscattering strength echoprofiles" were drawn, containing data about bathymetry and bottom surface backscattering. These new images are now comparable with data collected along the cruises were digital echograms were stored. All results were made available in a Geographic Information System (GIS).
\end{abstract}

Keywords: echosounder, bathymetry, GIS.

RESUMO. Informações referentes a ecossondagens de fundo, oriundas de sete cruzeiros de pesquisa foram armazenadas no banco de dados hidroacústicos do Laboratório de Tecnologia Pesqueira e Hidroacústica da FURG para validação, análise e interpretação. Os dados foram coletados através de ecossondas científicas operando na freqüência de $38 \mathrm{kHz}$, ao longo de 14.901 milhas náuticas, na plataforma continental, talude e região oceânica adjacente entre Fortaleza (CE) e Chuí (RS), Brasil. Uma análise visual dos ecogramas permitiu classificar o relevo do fundo em ecotipos de fundo e 80 imagens de ecogramas foram selecionadas. A partir dos dados de transectas perpendiculares à costa foram gerados 104 perfis batimétricos que cobrem toda a região de estudo. Durante a realização dos três primeiros cruzeiros (9.695 mn), realizados nas regiões sudeste e sul, não estava disponível software para armazenamento digital dos ecogramas. Para estes cruzeiros todos os dados batimétricos e de refletividade acústica do fundo pulso a pulso foram reprocessados e 137 ecoperfis de refletividade do fundo digitais foram gerados. Estas novas imagens, contendo batimetria e refletividade são passíveis de comparação com os cruzeiros onde ecogramas digitais foram armazenados. Todos os resultados foram disponibilizados em um Sistema de Informações Geográficas (SIG)

Palavras-chave: ecossonda, batimetria, SIG.

\footnotetext{
Fundação Universidade Federal do Rio Grande, Av. Itália, km 8, Campus Carreiros, Caixa Postal 474, 96203-000 Rio Grande, RS, Brasil. Fax: (53) 3233-6601

${ }_{1}^{1}$ Departamento de Oceanografia, Laboratório de Tecnologia Pesqueira e Hidroacústica, Tel.: (53) 3233-6528 - E-mail: ocecvc@furg.br

${ }^{2}$ Departamento de Oceanografia, Laboratório de Tecnologia Pesqueira e Hidroacústica, Tel.: (53) 3233-6555 - E-mail: doclsm@furg.br

${ }^{3}$ Departamento de Oceanografia Geológica, Laboratório de Oceanografia Geológica, Tel.: (53) 3233-6586 - E-mail: ggriep@log.furg.br

${ }^{4}$ Departamento de Oceanografia, Laboratório de Tecnologia Pesqueira e Hidroacústica, Tel.: (53) 3233-5743 - E-mail: mppinho@yahoo.com.br
} 


\section{INTRODUÇÃo}

Os oceanos tem sido foco de uma nova organização política desde 1982, quando foi assinada a Convenção das Nações Unidas sobre 0 Direito do Mar (CNUDM), que introduz e/ou consagra os conceitos de mar territorial, zona econômica exclusiva (ZEE) e plataforma continental (Souza, 1999). 0 Programa REVIZEE (Avaliação do Potencial Sustentável de Recursos Vivos na Zona Econômica Exclusiva), coordenado pelo Ministério do Meio Ambiente (MMA), foi iniciado em 1996 visando atender as obrigações desta convenção junto a ONU.

Ao longo do Programa, que teve por objetivo identificar os recursos vivos e estabelecer os potenciais de captura na ZEE brasileira, foram empregadas várias metodologias para amostrar 0 ambiente marinho, entre as quais o método denominado de prospecção acústica, gerando um rico banco de dados biológicos e batimétricos, obtidos ao longo de 16 cruzeiros de pesquisa de média a grande escala, isto é, da ordem de centenas a milhares de milhas.

Mesmo considerando o progresso científico e tecnológico da atualidade, ainda existem grandes dificuldades para obtenção de informações em ambientes oceânicos, decorrentes basicamente dos altos custos envolvidos. Consequentemente, dados obtidos em cruzeiros com metodologia acústica e que amostraram remotamente o fundo, apresentam-se como uma importante ferramenta para a identificação de características do fundo marinho (Figueiredo Jr. \& Madureira, 2004).

Atualmente a disponibilidade de dados, de fácil acesso, sobre os fundos submarinos da costa do Brasil, ainda é pequena. A metodologia acústica caracteriza-se por ser um método indireto e apresenta versatilidade e efetividade para auxiliar nas técnicas geológicas tradicionais de investigação submarina (Tegowski, 2005). Esse método também poder ser útil para a identificação e mapeamento de fundos coralíneos que, segundo Gundlach \& Hayes (1978), são locais de reconhecida sensibilidade ambiental e alvos de muitas discussões e conflitos.

Os fundos oceânicos adjacentes à costa brasileira, apesar de já terem sido objetos de estudos cientíícos que se valeram de variadas metodologias de observação, ainda se mostram como um vasto campo de pesquisa a ser explorado e detalhado uma vez que influenciam sob uma série de aspectos 0 ambiente marinho e, consequentemente, a exploração de seus recursos.

0 banco de dados de fundo, acusticamente coletados ao Iongo do Programa REVIZEE, constitui um grande acervo de informações com potencial para várias análises, mas, para tal, havia a necessidade de organizá-los e disponibilizá-los de forma ágil e de fácil acesso. 0 objetivo deste trabalho foi avaliar interpretar e organizar as informações referentes a registros de fundo, contidas neste banco de dados, coletado pelo Laboratório de Tecnologia Pesqueira e Hidroacústica, FURG, oriundas de 14.901 mn (milhas náuticas) de coleta de dados acústicos na área da costa brasileira compreendida entre Fortaleza (CE) e Chuí (RS).

Os fundos prospectados foram classificados de acordo com características morfológicas e a partir disto foi gerado um produto baseado em imagens, que apresenta a classificação dos fundos dentro dos perfis perpendiculares à costa, de forma a evidenciar a ocorrência de homogeneidades e heterogeneidades. 0 produto final foi um Sistema de Informações Geográficas (SIG), contendo todas as informações geradas além de um banco de ecogramas digitais.

\section{0 método hidroacústico}

0 equipamento básico para transmissão de som para 0 interior de um corpo d'água é denominado de ecossonda. Esses equipamentos são compostos de um transmissor, um transdutor, um receptor/amplificador, uma base de tempo e um monitor. A base de tempo gera um sinal elétrico para ligar o transmissor, o qual produz um pulso de frequêencia " $f$ " e duração " $\tau$ " para energizar 0 transdutor. A energia elétrica é convertida pelo transdutor em energia acústica que é transmitida para a água, "insonificando" os objetos em sua trajetória. Os "ecos" destes objetos retornam, são convertidos em energia elétrica pelo processo reverso do transdutor, amplificados e corrigidos para as perdas por atenuaçã̃o e espalhamento geométrico. Esta correção é feita pelo sistema de ganho crono-variado (Função TVG - Time Varied Gain).

Para cada pulso são processados os sinais de retorno ou ecos, e disponibilizados na forma de uma "imagem", cuja origem é acústica, que representa a disposição dos alvos (objetos) detectados ao longo da propagação do som. 0 registro dos sinais acústicos se chama ecotraço, e corresponde à representação gráfica da energia dos alvos, 0 resultado da seqüência de impressão de ecotraços é chamado de ecograma, correspondendo à informação acústica básica e, em geral, a primeira a ser analisada (Gerlotto, 1996).

Equipamentos acústicos científicos processam a energia refletida pela superfície do fundo oceânico denominada de Força de Retroespalhamento da Superfície do Fundo (Bottom Surface Backscattering Strength ou BSBS). A proporção de energia refletida é determinada pelo coeficiente de reflexão, que por sua vez é função da impedância acústica do meio (água) e do refletor, nesse caso o fundo (MacLennan \& Simmonds, 1992). 
A parte da onda que atinge 0 fundo e retorna ao transdutor representa a energia retro-espalhada (backscattered). Fundos planos e irregulares apresentam diferentes graus de espalhamento de energia assim como as propriedades físicas também influenciam significativamente na resposta. Formas sedimentares como marcas de ondulação (ripple marks), a textura das rochas e os organismos que vivem no fundo também influenciam no sinal (Collins et al., 1996). 0 equipamento utilizado para este trabalho disponibiliza o parâmetro Bottom Surface Backscattering Strength em dB (decibel), que representa uma relação logarítmica entre a Intensidade do sinal que atinge o fundo e que é refletido pelo mesmo.

\section{METODOLOGIA \\ Coleta de dados}

Foram analisados dados hidroacústicos provenientes de sete cruzeiros de pesquisa, realizados entre 1996 e 2004, cobrindo uma área que se estende do Chuí ( $\left.34^{\circ} 44^{\prime} \mathrm{S}\right)$ a Fortaleza $\left(03^{\circ} 43^{\prime} \mathrm{S}\right)$, tendo amostrado a plataforma continental, talude e regiões oceânicas, perfazendo um total de 14.901 milhas náuticas de prospecção (Fig. 1).

Para a coleta de dados acústicos, utilizaram-se ecossondas científicas SIMRAD EK500 e OSSIAN 1500, operando na freqüência de $38 \mathrm{kHz}$, calibradas de acordo com o método da esfera padrão (MacLennan \& Simmonds, 1992). As ecossondas estavam conectadas a aparelho de navegação do tipo GPS e recebendo dados de latitude e longitude de forma regular. Além de digitalmente armazenados, os dados foram impressos sob a forma de ecogramas e, nos cruzeiros a partir de 1999, imagens digitais foram armazenadas com o software MOVIES + 3.1. Os dados brutos coletados foram filtrados isolando somente os parâmetros de interesse para o presente trabalho, neste caso as informações batimétricas, posicionamento geográfico e os dados de refletividade acústica do fundo, ou BSBS (Bottom Surface Backscattering Strength).

\section{Perfis batimétricos}

Perfis batimétricos foram elaborados através dos dados de profundidade coletados em transectas com orientação perpendicular à costa, considerando uma distância padronizada (eixo x) de $140 \mathrm{mn}$ e uma profundidade (eixo y) de $2.500 \mathrm{~m}$. A distância entre a linha de costa e o início de cada perfil também foi considerada.

\section{Caracterização do relevo de fundo}

0 relevo de fundo foi caracterizado através da análise visual minuciosa do universo de ecogramas disponíveis, tanto impressos quanto digitais. Com isso classificaram-se "ecotipos de fundo", definidos como um alvo (no caso, o fundo) enquadrado dentro de um padrão com características definidas e morfologicamente consistentes e que englobam um conjunto contíguo de registros.

\section{Ecoperfis de refletividade de fundo}

Nos três primeiros cruzeiros a ecossonda foi configurada para apresentar apenas o contorno do fundo, o que não permite a análise gráfica de diferenças na refletividade do fundo. Para proceder a esta análise realizou-se uma reconstrução digital do fundo, a partir da geração de "ecoperfis de refletividade de fundo", a partir dos dados de BSBS armazenados.

Os valores de reflexão acústica do fundo (BSBS), em decibéis (dB) foram agrupados em quatro classes, diferenciadas por cores, de acordo com Figueiredo Jr. \& Madureira (2004):

- -5 até -10 dB: Representada nos perfis pela cor vermelha;

- -10 até $-15 \mathrm{~dB}$ : Representada nos perfis pela cor amarela;

- -15 até -20 dB: Representada nos perfis pela cor verde;

- $<-20 \mathrm{~dB}$ : Representada nos perfis pela cor azul.

Segundo Figueiredo Jr. \& Madureira (2004), estas quatro classes de valores de reflexão acústica, em decibéis, podem ser correlacionadas a 10 classes sedimentares definidas, a partir do diagrama triangular tipo Shepard, sendo que, quanto mais "duro" ou "compactado" é o fundo, maior a reflexão. Portanto, o azul representa os fundos menos refletivos ou de característica lamosa e o vermelho representa fundos duros ou mais refletivos.

A largura do traço do fundo adotado nos perfis reconstruídos também manteve uma proporcionalidade com os valores de reflexão do fundo, sendo mais finos nos registros de maior valor de BSBS (fundo duro; menor penetração do som no sedimento), e mais grossos nos de menor valor de BSBS (fundo mole; maior penetração do som no sedimento).

\section{Sistema de Informações Geográficas - SIG}

Através do uso do software ArcView 3.2. foi elaborado um Sistema de Informações Geográficas (SIG) da área de estudo, contendo o desenho amostral dos cruzeiros, os perfis batimétricos e a classificação morfológica para cada transecta, além das imagens de ecogramas selecionadas e os ecoperfis de refletividade. Como complementação incluíram-se, com o devido georreferenciamento, os blocos de exploração de petróleo concedidos nas 


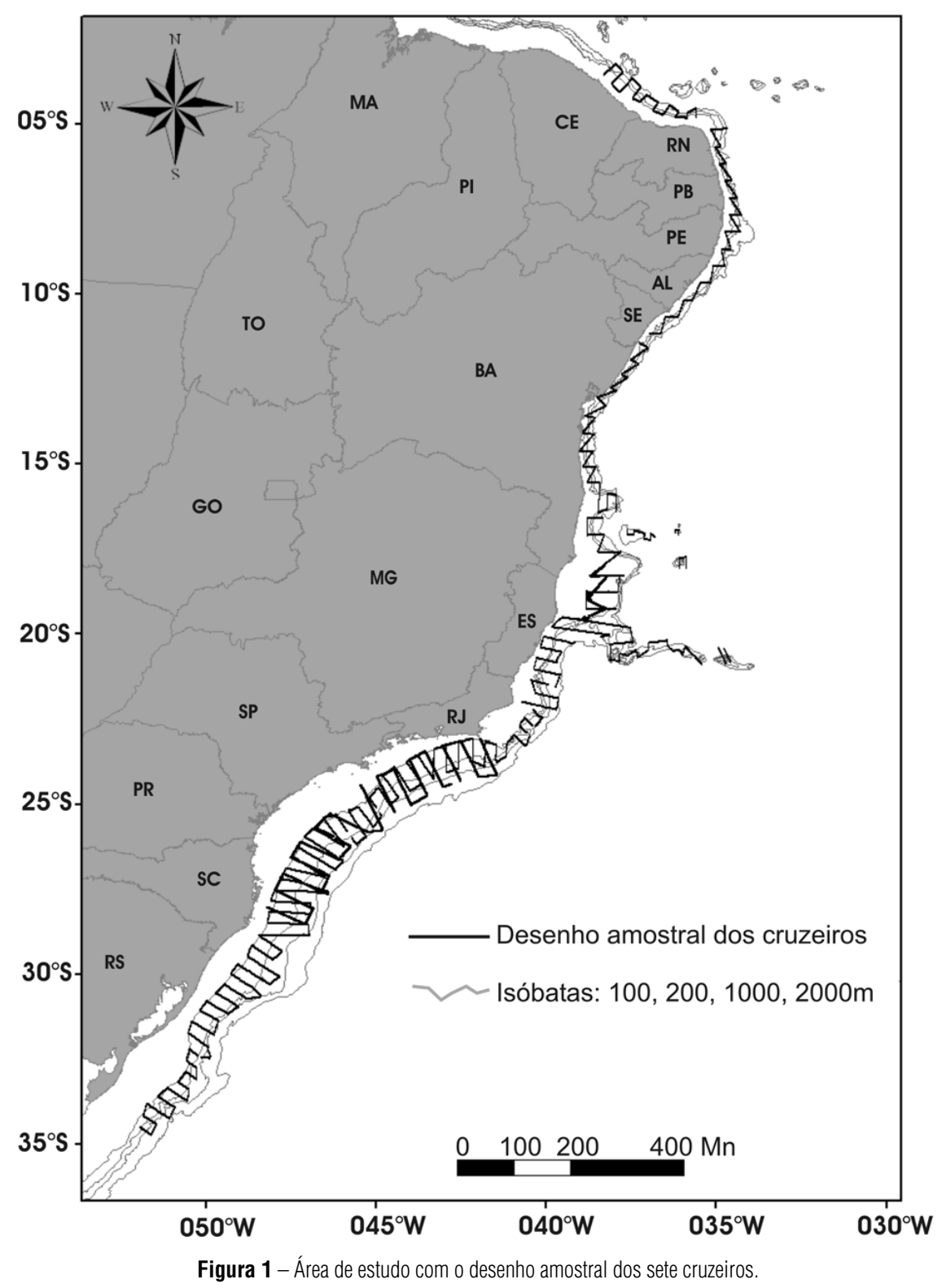

sete rodadas de licitações realizadas pela Agência Nacional do Petróleo, Gás Natural e Biocombustíveis (ANP) e Cartas de Sedimento de Fundo produzidas por Dias et al. (2004), como resultado do Programa REVIZEE.

\section{RESULTADOS E DISCUSSÃO}

\section{Perfis batimétricos}

Foram elaborados 104 perfis batimétricos distribuidos ao longo da costa, desde Fortaleza ao Chuí. Todos os perfis estão apresentados com exagero vertical de 103 vezes.
A análise dos perfis batimétricos da plataforma da região nordeste (Fortaleza à Salvador) evidenciaram sua pequena extensão, com média de $40 \mathrm{~km}$, sendo mais e menos extensos, respectivamente, próximo à Fortaleza, com 65 km (Fig. 2), e em frente à Salvador, com 16 km (Fig. 3). A análise evidencia ainda a abrupta quebra da plataforma encontrada entre os 60 e $80 \mathrm{~m}$ e a forte inclinação do talude com a presença de muitas irregularidades, principalmente formadas por grandes vales e canyons.

A largura da plataforma na região central (Salvador ao Cabo de São Tomé) apresentou-se variável, com média de 24 km até 0 Banco Royal Charlotte, a partir do qual se alarga. Os mínimos e 

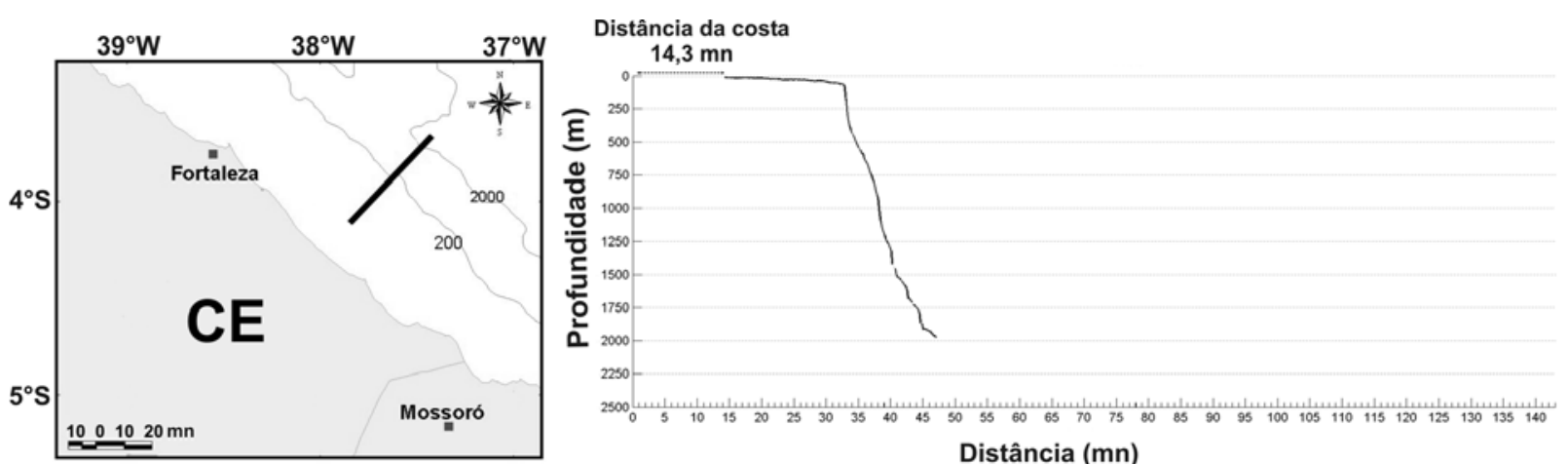

Figura 2 - Perfil batimétrico de uma transecta realizada próxima a Fortaleza.
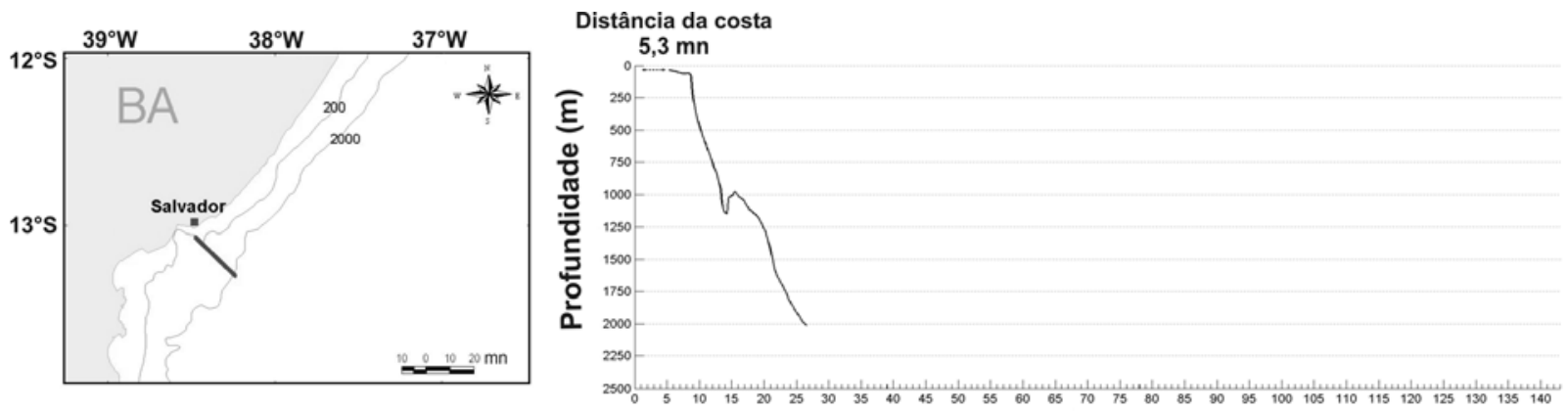

Distância (mn)

Figura 3 - Perfil batimétrico de uma transecta realizada em frente a Salvador.

máximos foram de 11 km entre Salvador e llhéus (Fig. 4) e 203 km sobre 0 banco de Abrolhos (Fig. 5), respectivamente. A quebra da plataforma permanece bem marcada, em torno dos $70 \mathrm{~m}$. 0 talude apresenta-se menos irregular que na região nordeste, apesar de alguns canyons.

Entre São Tomé e Chuí (Região Sul) a plataforma apresenta-se extensa, sendo mais estreita nas proximidades de Cabo Frio (RJ) e do Cabo de Santa Marta Grande (SC) (Fig. 6) e apresentando maior largura próxima a Santos (230 km), sobre o Embaiamento de São Paulo (Fig. 7), estreitando-se novamente ao sul (média de $180 \mathrm{~km}$ ). A quebra da plataforma, menos marcada e quase imperceptível em determinados perfis, situa-se entre 120 e $150 \mathrm{~m}$ ao norte de Santos, e em torno de $200 \mathrm{~m}$ ao sul. 0 talude apresentase com menor inclinação e mais plano que nas outras regiões.

\section{Caracterização do relevo de fundo}

A análise dos ecogramas foi focada principalmente nas transectas perpendiculares à costa, mas também foram obtidas informações nas demais transectas. A forma de coleta dos dados permitiu uma leitura milha a milha dos ecogramas e a classificação de setores das transectas em seis classes: liso, irregular, corais, canais, arrastável e pós-quebra.

Considerou-se como fundo liso (Fig. 8A), todo fundo livre de irregularidades como elevações, depressões ou qualquer outra estrutura que afetasse sua linearidade em macro-escala, sendo os que não se enquadraram nesta categoria classificados como irregulares (Fig. 8B). Os fundos classificados como lisos foram identificados em $28,7 \%$ do total de dados analisados, enquanto que os fundos irregulares apareceram em 7,3\% no total analisado.

Os corais e os canais são tipos de fundo irregulares que por possuírem características próprias foram classificados como ecotipos distintos. Os registros classificados como coralíneos (Fig. 9) apresentaram irregularidades diferenciadas no fundo, com picos de até $10 \mathrm{~m}$ de altura e até $100 \mathrm{~m}$ de base, que se afinam em direção a superfície, repetindo-se consecutivamente com pequenos intervalos. Este tipo de registro foi observado em águas rasas (até $50 \mathrm{~m}$ ), e altamente concentrado sobre o Banco de Abrolhos. A ocorrência de registros classificados como corais representou $0,3 \%$ do total analisado.

No ecotipo denominado canais (Fig. 10) foram inseridos registros de feições negativas, representando canyons, ravinas ou paleocanais. A ocorrência de registros classificados como canais 

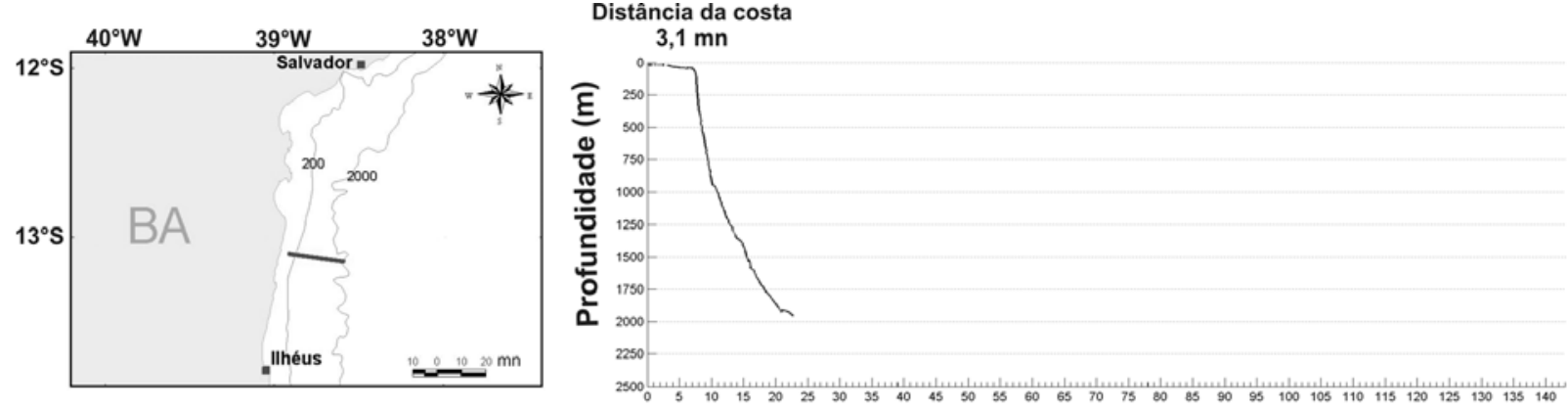

Distância (mn)

Figura 4 - Perfil batimétrico de uma transecta realizada entre Salvador e llhéus.
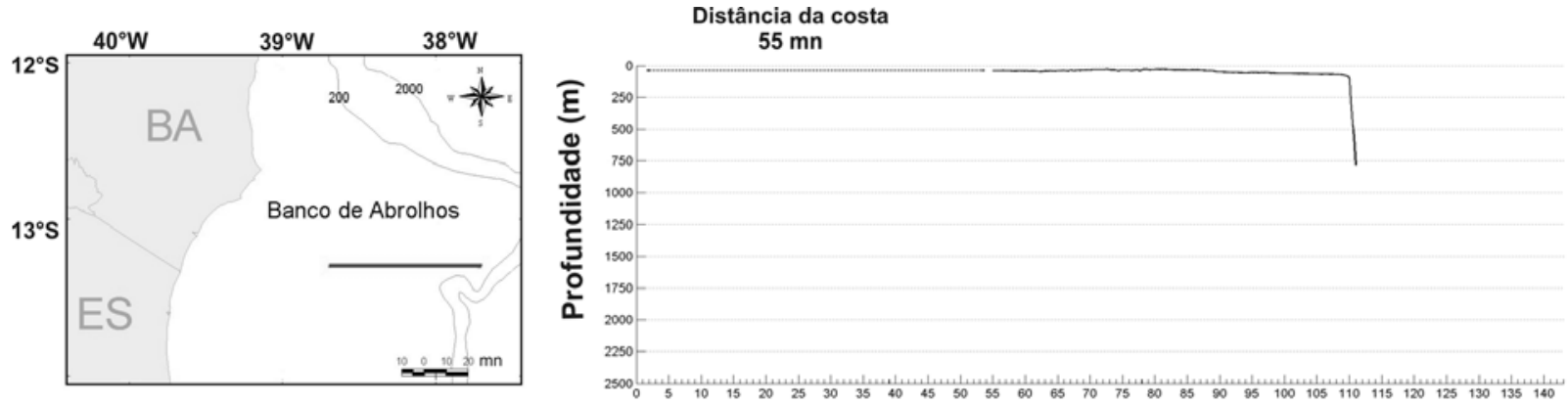

Distância (mn)

Figura 5 - Perfil batimétrico de uma transecta realizada sobre o Banco de Abrolhos.
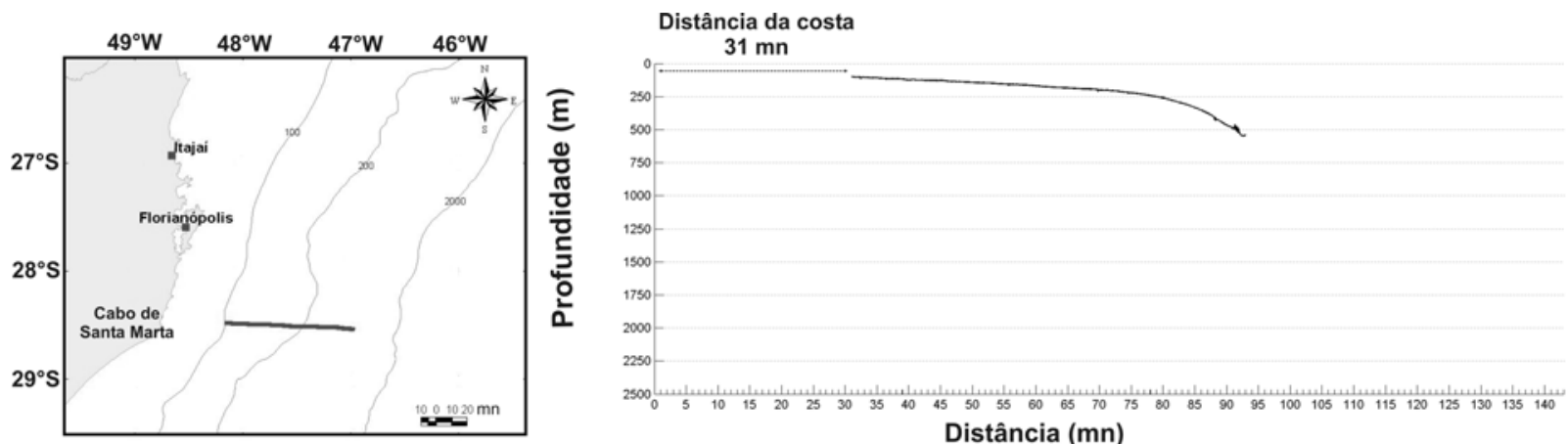

Figura 6 - Perfil batimétrico de uma transecta realizada ao sul do Cabo de Santa Marta Grande.

foi rara nos perfis analisados ( $<0,03 \%)$, pois na maioria das vezes os canais têm uma orientação perpendicular à linha de costa. Esse posicionamento dificulta sua identificação em dados coletados no mesmo sentido, perfis e feições de fundo ortogonais à costa. Uma análise dos ecogramas de perfis paralelos à costa demonstrou a ocorrência freqüente destes canais.

Para fins de pesca foi considerada ainda a classe "fundo arrastável", definida como todo fundo liso (Fig. 8A), com baixa declividade $(<20 \mathrm{~m} / \mathrm{mn})$, poucas irregularidades e livre de cabeços ou outras estruturas, e que se mantenha assim por, pelo menos, $10 \mathrm{mn}$ de extensão. Esta classe representou 15,8\% do total de dados analisados.

Toda a caracterização foi restrita a região de plataforma continental. Todos os registros após a quebra da plataforma foram inseridos na classe "pós-quebra" que representaram 46\% dos dados, concentrados principalmente no talude superior. Esses dados não sofreram uma avaliação mais minuciosa do relevo de fundo, em função da freqüência utilizada (38 kHz) e da elevada 

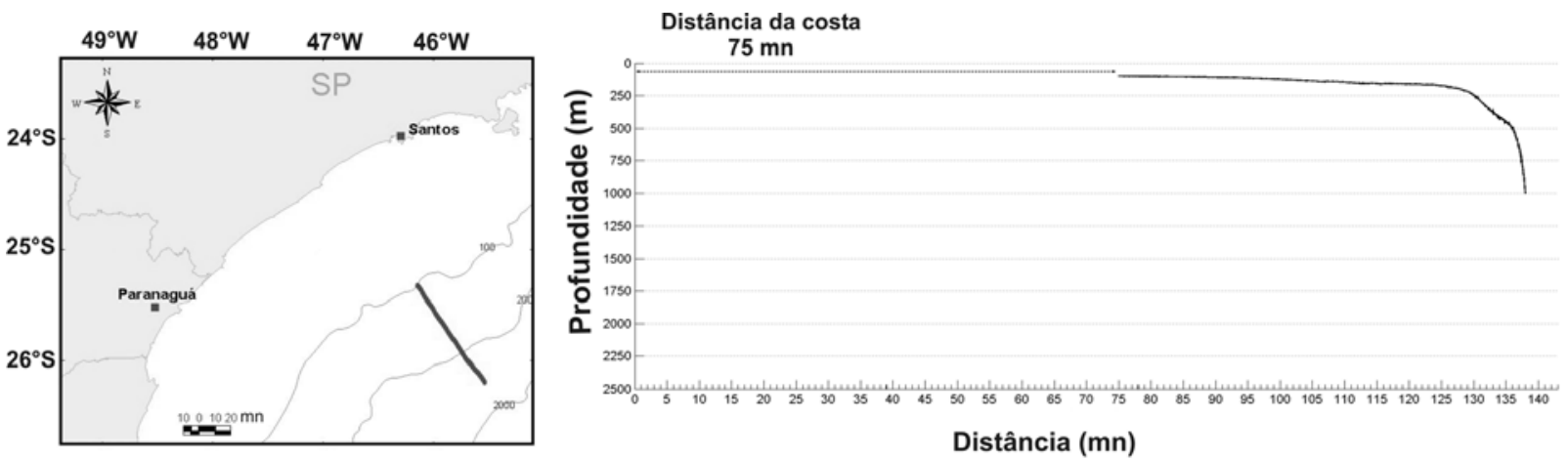

Figura 7 - Perfil batimétrico de uma transecta realizada sobre o Embaiamento de São Paulo.
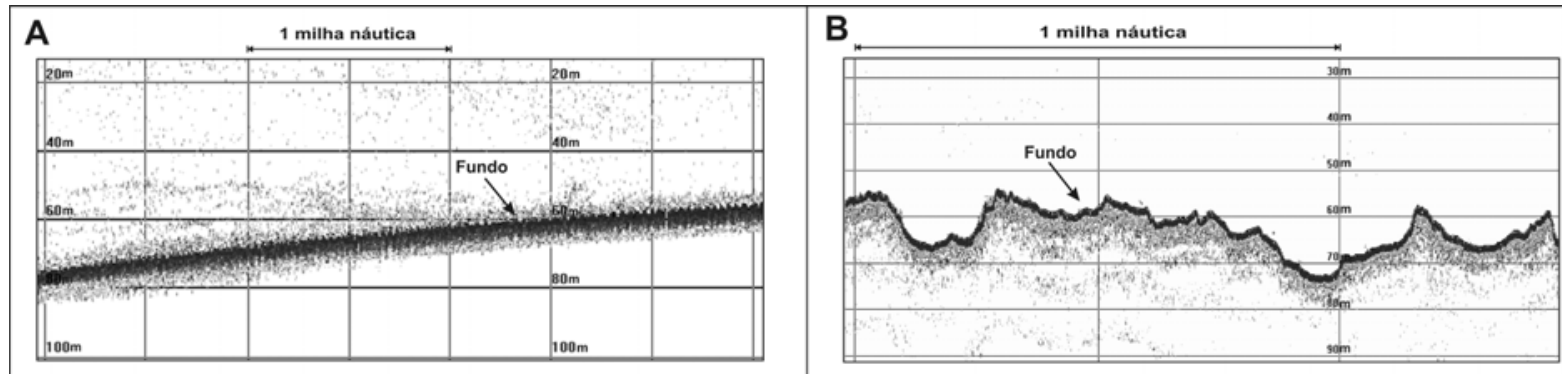

Figura 8 - Ecogramas de fundos classificados como ecotipos liso (A) e irregular (B).

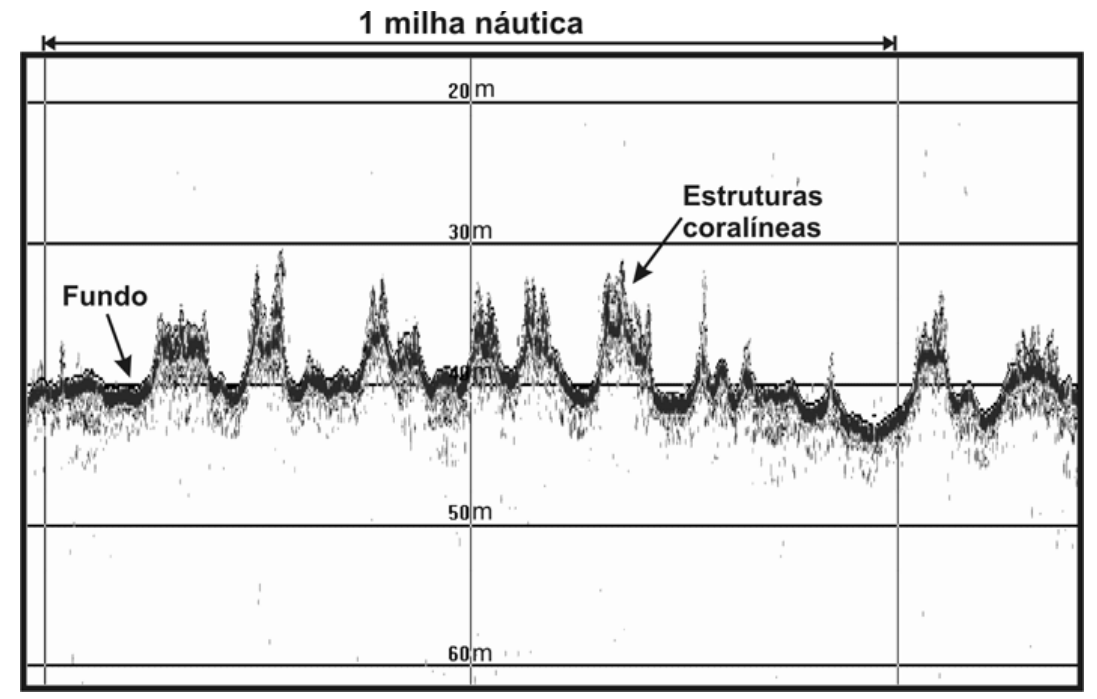

Figura 9 - Ecograma de um fundo classificado como ecotipo coralíneo.

distancia entre transdutor e 0 fundo. A Fig. 11 apresenta um exemplo de ecograma de quebra da plataforma.

Os percentuais de ocorrência das classes de fundo também foram calculados para cada uma das áreas (Tab. 1), uma vez que o esforço amostral não foi padrão. Na região sul foram prospec- tados e analisados quatro cruzeiros enquanto que somente um foi realizado em cada uma das regiões central e nordeste.

A análise das informações da região nordeste mostra uma concentração de dados após a quebra da plataforma, que somam $53 \%$ do total analisado. Isso se deve a reduzida largura da plata- 


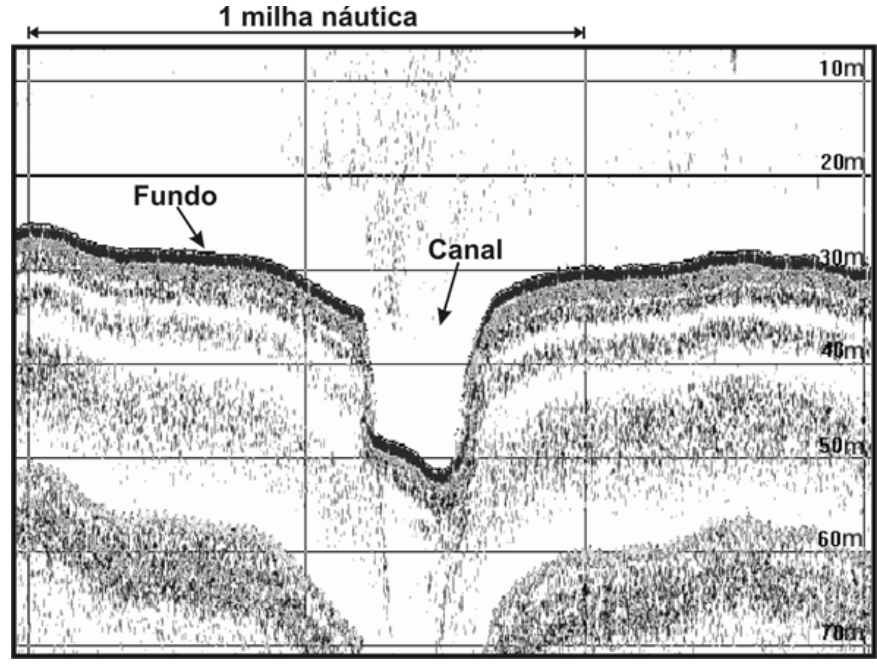

Figura 10 - Ecograma de fundo com ecotipo canal.

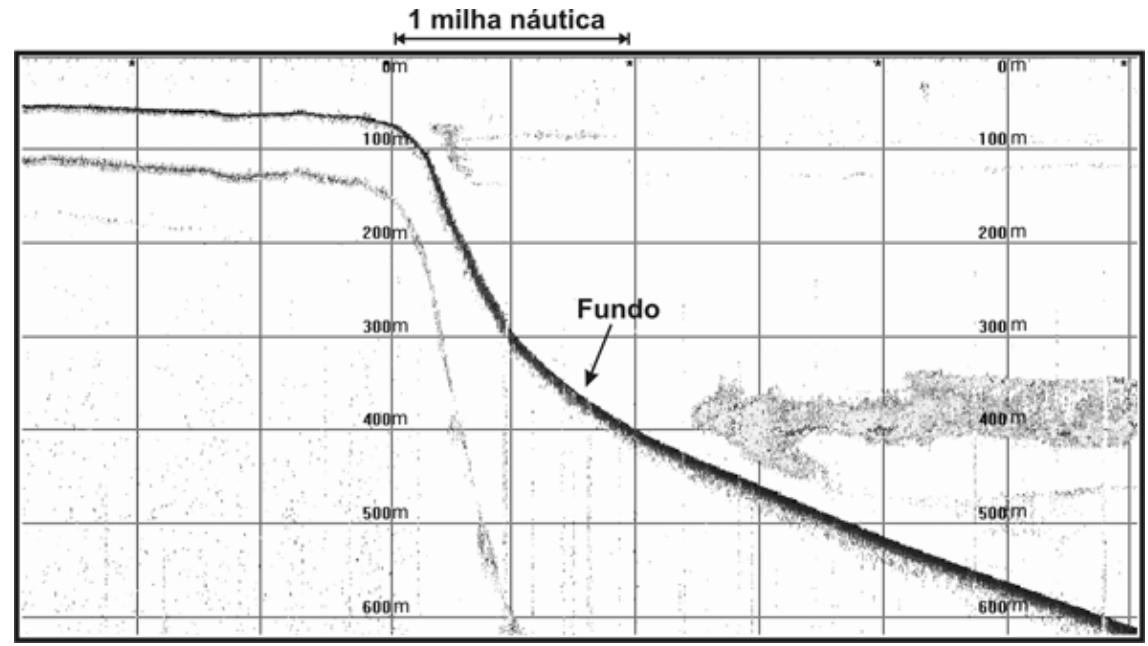

Figura 11 - Ecograma de uma região de quebra da plataforma.

Tabela 1 - Percentuais de ocorrência das classes de fundo para cada uma das três regiões.

\begin{tabular}{|c|c|c|c|c|c|c|c|}
\hline \multirow{2}{*}{ Região } & Milhas náuticas & \multicolumn{6}{|c|}{ Percentual de classes de fundo } \\
\cline { 3 - 8 } & prospectadas & Arrastável & Liso & Irregular & Pós-quebra & Coral & Canal \\
\hline Nordeste & 317 & $13 \%$ & $28 \%$ & $6 \%$ & $53 \%$ & - & $<0,01 \%$ \\
\hline Central & 989 & $15 \%$ & $19 \%$ & $10 \%$ & $53 \%$ & $3 \%$ & $<0,1 \%$ \\
\hline Sul & 7960 & $31 \%$ & $15 \%$ & $7 \%$ & $45 \%$ & - & $<0,01 \%$ \\
\hline
\end{tabular}

${ }^{*}$ Os valores percentuais de classes de fundo foram arredondados. Para a região Sul aproximadamente $2 \%$ foram milhas não analisadas.

forma continental na região, o que responde também pela baixa porcentagem de fundos arrastáveis (13\%).

Nos perfis analisados para essa região não foram encontrados registros de ecotipo coral e somente um canal foi registrado a
60 km ao sul de Recife (PE), com aproximadamente $20 \mathrm{~m}$ de profundidade e apresentando no sentido oceano-continente, a primeira borda ligeiramente mais baixa que a segunda (Fig. 12). Considera-se que o canal identificado possa estar representando 


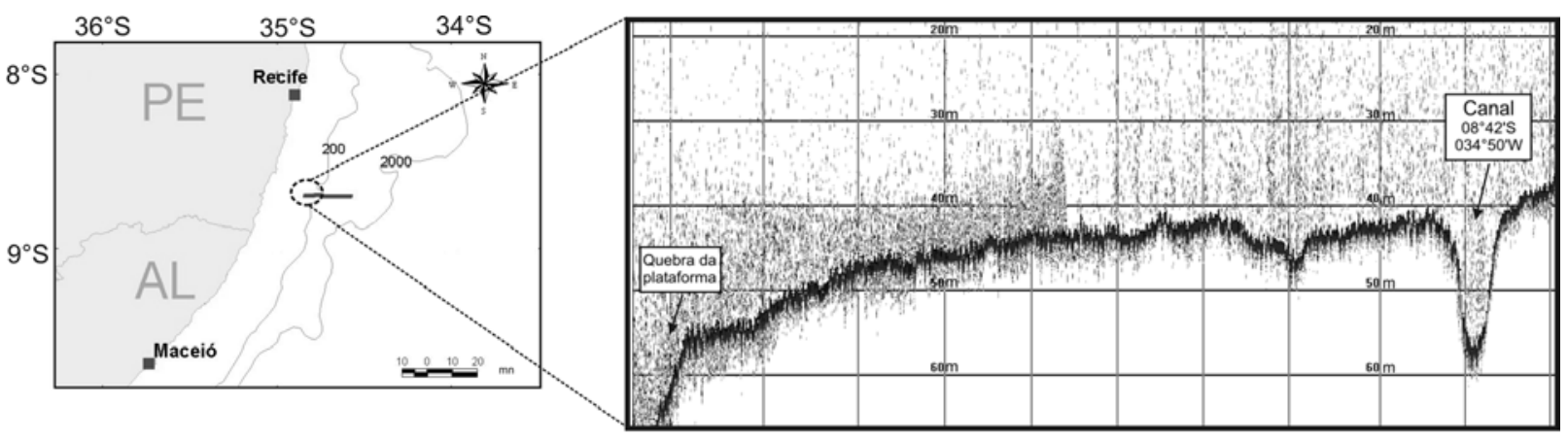

Figura 12 - Canal encontrado a 60 km ao sul de Recife (PE) em perfil perpendicular à costa.

um meandramento para o sul, de alguns dos paleocanais encontrados na região (Zembruscki, 1979; França, 1979; Coutinho, 1996). Ao sul de Recife encontra-se o rio Pirapema, cujo canal também pode estar associado.

Na região Central, como na região Nordeste, ocorreu uma maior concentração dos dados em áreas pós-quebra da plataforma, isto se deve a pouca largura da mesma, sendo esta estreita até 0 Banco de Abrolhos, justamente onde os perfis tiveram seu inicio mais distantes da costa. Dos 47\% dos dados localizados sobre a plataforma, a maioria foi encontrada sobre fundos lisos ou arrastáveis. Os fundos arrastáveis se concentraram em áreas de alargamento da plataforma, como na borda externa do Banco de Abrolhos. Cabe ressaltar que a classificação "arrastável" foi baseada somente na morfologia do fundo. Implicações ecológicas do arrasto, sabidamente uma atividade que afeta o fundo (Committee on Ecosystem Effects of Fishing, 2002), não foram consideradas neste estudo. No entanto o georreferenciamento de regiões arrastáveis sobre o Banco de Abrolhos pode ser de grande valia para a criação de futuras áreas de proteção, uma vez que estes fundos já devem estar sob intensa atividade pesqueira. A parte mediana deste banco foi o local de maior concentração do ecotipo coral, representando aproximadamente $3 \%$ do total analisado. A maioria desses registros de corais faz parte do arco externo que se localiza a cerca de 70 km da costa, a leste do Arquipélago e é formado por chapeirões isolados que não se coalescem lateralmente formando bancos recifais, como ocorre no arco costeiro, localizado mais próximo da costa (Leão, 1999).

Um canal foi identificado a aproximadamente $20 \mathrm{~km}$ a frente de Vitória, ES (20²4'S, $040^{\circ} 08^{\prime} \mathrm{W}$ - Fig. 10). Coutinho (1996) relaciona estes estreitos vales a movimentação submarina de carga sedimentar do Rio Doce, que deságua ao norte. 0 canal encontrado pode estar representando uma bifurcação dos vales descritos para a região.
A região sul apresentou a maior concentração de perfis. Do total destes, $45 \%$ corresponderam a áreas posteriores à quebra da plataforma, 53\% sobre a plataforma e, em 2\%, não foi possível a classificação, ou por não terem tido seus ecogramas impressos ou por problemas no georreferenciamento. Dos dados sobre a plataforma continental, há grande predominância de fundos classificados como lisos. Essa diferença marcante entre as regiões nordeste, central e sul, pode ser explicada pela extensa plataforma desta última.

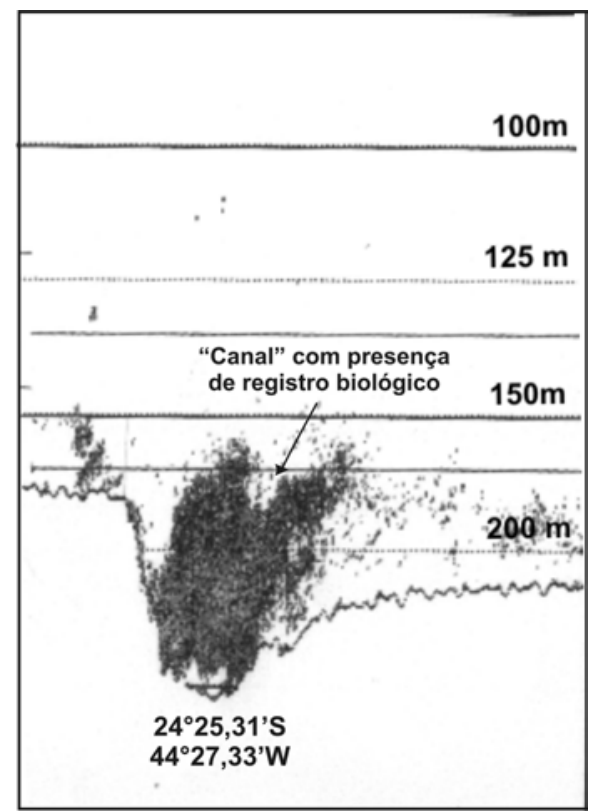

Figura 13 - Canal encontrado a $100 \mathrm{~km}$ da costa, em frente a ilha de São Sebastião (SP).

Não ocorreram registros do ecotipo coral na região sul e somente um canal a $100 \mathrm{~km}$ da costa (Fig. 13), em frente à ilha de São Sebastião (SP), que por ter uma borda mais alta que a outra pode estar representando uma ravina causada por 


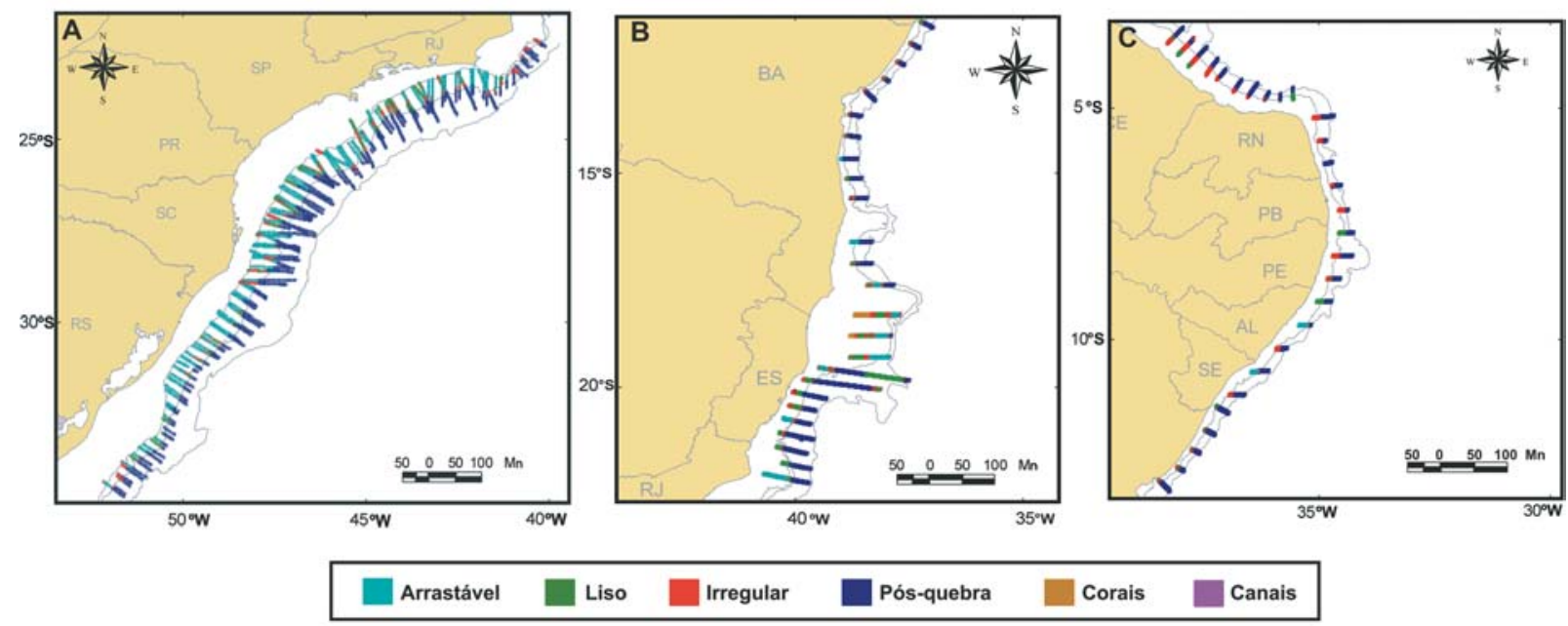

Figura 14 - Caracterização do relevo de fundo da área de estudo. A: região Sul, B: região Central e C: região Nordeste.

um provável deslizamento ou também estar representando um terraço de abrasão, já que se encontra muito próximo à quebra da plataforma.

Três mapas da área de estudo com os desenhos amostrais e as respectivas classificações do relevo de fundo para cada região: Nordeste, Central e Sul estão apresentados na Fig. 14.

\section{Ecoperfis de refletividade de fundo}

A análise de 138 ecoperfis de refletividade de fundo permitiu interpretar relações entre a refletividade acústica (BSBS) e as características sedimentológicas dos mesmos. Estes mostraram coerência com informações de Cartas de Sedimento de Fundo (Dias et al., 2004).

Um padrão observado foi a concentração de maiores coeficientes de reflexão acústica $(-5 \mathrm{a}-10 \mathrm{~dB})$ sobre a plataforma externa e quebra, intercalados com coeficientes de $-10 \mathrm{a}-$ $15 \mathrm{~dB}$, e províncias com menores coeficientes de reflexão acústica (>-20 dB) concentrando-se sobre o talude continental (Fig. 15). Estes valores são compatíveis com a deposição de sedimentos mais finos no talude devido a maior hidrodinâmica na plataforma e quebra.

Perfis homogêneos com coeficientes menores que $-20 \mathrm{~dB}$, representando fundos totalmente cobertos por sedimentos lamosos, foram observados principalmente na costa sul do Rio Grande do Sul, em áreas de influencia fluvial, como mostrado na Fig. 16.

\section{Seleção de imagens}

Ao realizar a caracterização do relevo de fundo, muitas feições dignas de atenção foram selecionadas para posterior inserção num banco de imagens. Porém, durante a realização desta análise, foram encontradas feições interessantes nas inter-transectas e áreas oceânicas profundas, regiões as quais não eram 0 objetivo principal do trabalho. Alguns destes ecoregistros foram selecionados e compõem o banco de imagens, que totaliza 80 imagens de ecogramas.

0 tipo de registro mais marcante observado nas inter-transectas foram os canais, raramente observados nas transectas perpendiculares à costa. Os canais foram observados predominantemente sobre a plataforma continental, distribuídos por toda a área de estudo. A maior concentração esteve sobre a costa do estado da Bahia (Fig. 17).

Ao sul do rio Belmonte, sobre a parte interna do banco Royal Charlotte, foram encontrados diversos pequenos canais entre 50 e $60 \mathrm{~m}$, com 10 a $20 \mathrm{~m}$ de profundidade e variando entre 200 e $600 \mathrm{~m}$ de largura (Fig. 17A e B). Exemplos interessantes também foram encontrados na desembocadura dos rios do Frade e Caraíva, em aproximadamente $30 \mathrm{~m}$ de profundidade. Segundo França (1979), neste trecho de estreitamento da plataforma, entre Porto Seguro (BA) e Alcobaça (BA), os canais compõem um padrão de drenagem dendrítica e podem estar geneticamente relacionados ao escoamento pretérito, através da superfície hoje afogada, dos rios Itanhém, Jucurucu, Caraíva e do Frade. Foram observados três canais em cada um dos dois registros de perfis paralelos à costa, em frente aos rios (Fig. 17C e D). Estes canais, lado a lado, podem representar o escoamento dos vários rios citados ou o meandramento de dois canais formados pelo escoamento pretérito dos rios Caraíva e do Frade, localizado diretamente a frente dos perfis. 

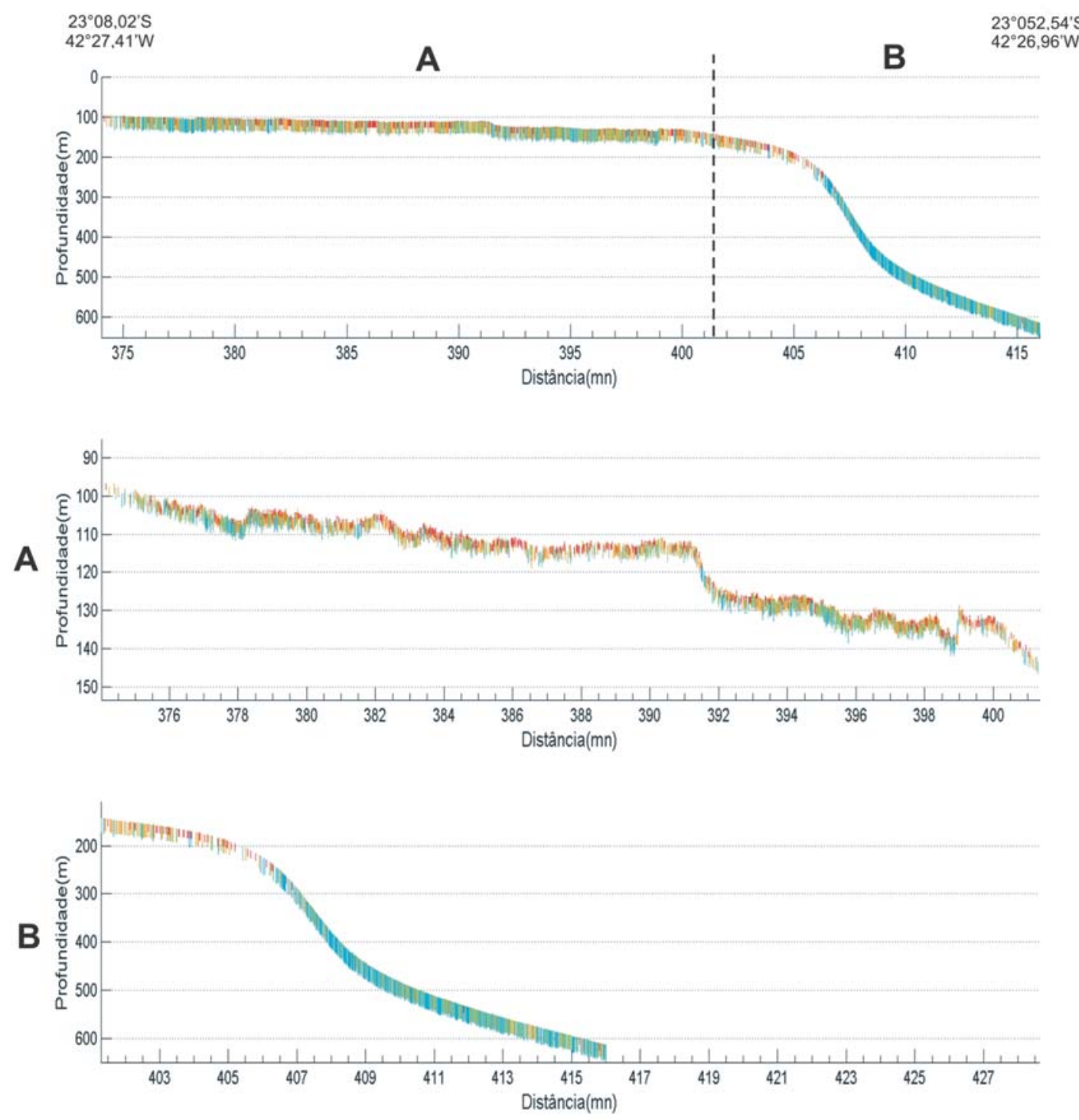

\section{\begin{tabular}{|l|l||l|}
\hline-5 até $-10 \mathrm{~dB}$ & -10 até $-15 \mathrm{~dB}$ & -15 até $-20 \mathrm{~dB} \quad$ Menor ou igual a $-20 \mathrm{~dB}$ \\
\hline
\end{tabular}}

Figura 15 - Ecoperfil de fundo gerado a partir de dados de profundidade e dureza de fundo. A e B são subdivisões do primeiro perfil visando maior detalhamento das feições.

Também foram encontrados pequenos paleocanais na parte central do banco de Abrolhos (Fig. 17E). França (1979) supõe que os canais hoje observados no Banco de Abrolhos tiveram seu topo preenchido por uma pobre, mas contínua sedimentação proveniente da costa, carreada, entre outros agentes, pelos rios Peruípe, Mucuri e São Mateus, todos encaixados no flanco oeste do banco. Trata-se de feições relíquias que foram preservadas do soterramento em face da própria insuficiência da carga sedimentar daqueles rios, bloqueada por barras que Ihe restringem 0 deslocamento através da plataforma.

Uma feição interessante que ocorre no talude inferior, em torno dos $700 \mathrm{~m}$ de profundidade, são os "pockmarks", descritos por Sumida et al. (2004) como estruturas tipo crateras, de fundos moles de granulometria fina, comumente encontradas ao longo 


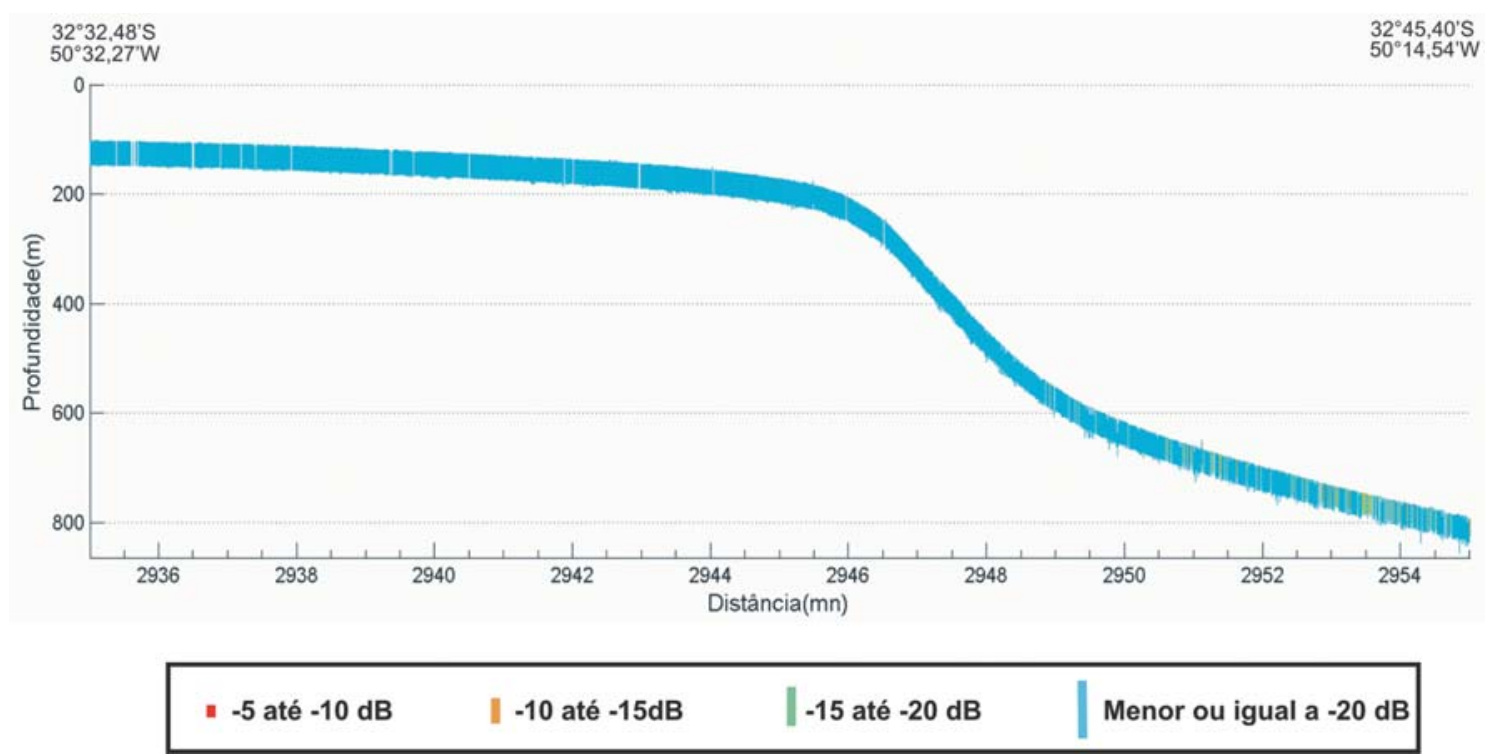

Figura 16 - Ecoperfil de fundo gerado a partir de dados de profundidade e dureza de fundo obtidos em frente a Rio Grande, RS. A cor azul representa valores de $\mathrm{BSBS} \leq-20 \mathrm{~dB}$.

da margem continental, atribuídos a episódicas e catastróficas expulsões de fluidos. Os registros apresentam formas circulares a elípticas (Fig. 18).

\section{Sistema de Informações Geográficas - SIG}

0 SIG gerado neste trabalho permite o acesso rápido aos dados, além de possibilitar o cruzamento de informações para melhor interpretação dos resultados. Consiste na reunião dos resultados em um mapa georreferenciado da costa brasileira, no qual foram inseridas, sob a forma de "links" as seguintes informações:

a) 104 imagens dos perfis batimétricos;

b) 137 imagens dos ecoperfis de refletividade de fundo;

c) 80 imagens de ecogramas de diferentes feições ao longo da costa brasileira.

A classificação do relevo de fundo, realizada milha a milha, está disponibilizada sobre 0 desenho amostral na forma de cores diferentes para cada classe encontrada: liso, irregular, coral, canal, arrastável e pós-quebra.

Além disso, para efeito de complementação, foram inseridos no SIG as Cartas de Sedimento de Fundo geradas por Dias et al. (2004). Esses mapas permitiram, por exemplo, a constatação de que registros que anteriormente classificados como coral podem estar relacionados também a algas calcárias.

Também foi inserida a localização dos blocos de exploração de petróleo desde a primeira rodada de licitações até os oferecidos na sétima rodada, em 2005. Ao analisar a localização destes blocos percebe-se que grande parte dos dados utilizados neste trabalho localiza-se em áreas de interesse da indústria do petróleo. Portanto, o maior detalhamento das feições presentes nesta região pode contribuir para o conhecimento necessário na realização de várias operações indispensáveis da exploração de petróleo como, por exemplo, a colocação de dutos submarinos.

\section{CONCLUSÃO}

0 presente trabalho demonstra que cruzeiros dirigidos à prospecção acústica pesqueira geram informações que, devidamente identificadas no seu potencial, podem acrescentar novos dados batimétricos e geológicos as regiões de estudo. É importante salientar também que, no Brasil, poucos cruzeiros de pesquisa são de larga escala espacial e que navios bem equipados com equipamentos acústicos sofisticados podem trazer informações valiosas, mesmo quando operando para fins diversos, tais como, mapeamento de estoques pesqueiros, objetivo principal dos cruzeiros ora analisados.

0 trabalho apresenta de forma organizada e de fácil acesso uma substancial coleçãa de informações geradas a partir da utilização de ecossondas cientificas ao longo de 14.901 milhas náuticas, dispostas ao longo das regiões nordeste, central e sul do Brasil.

A alta taxa amostral proporcionada pelo método acústico permite uma resolução de feições de fundo da ordem de metros, 

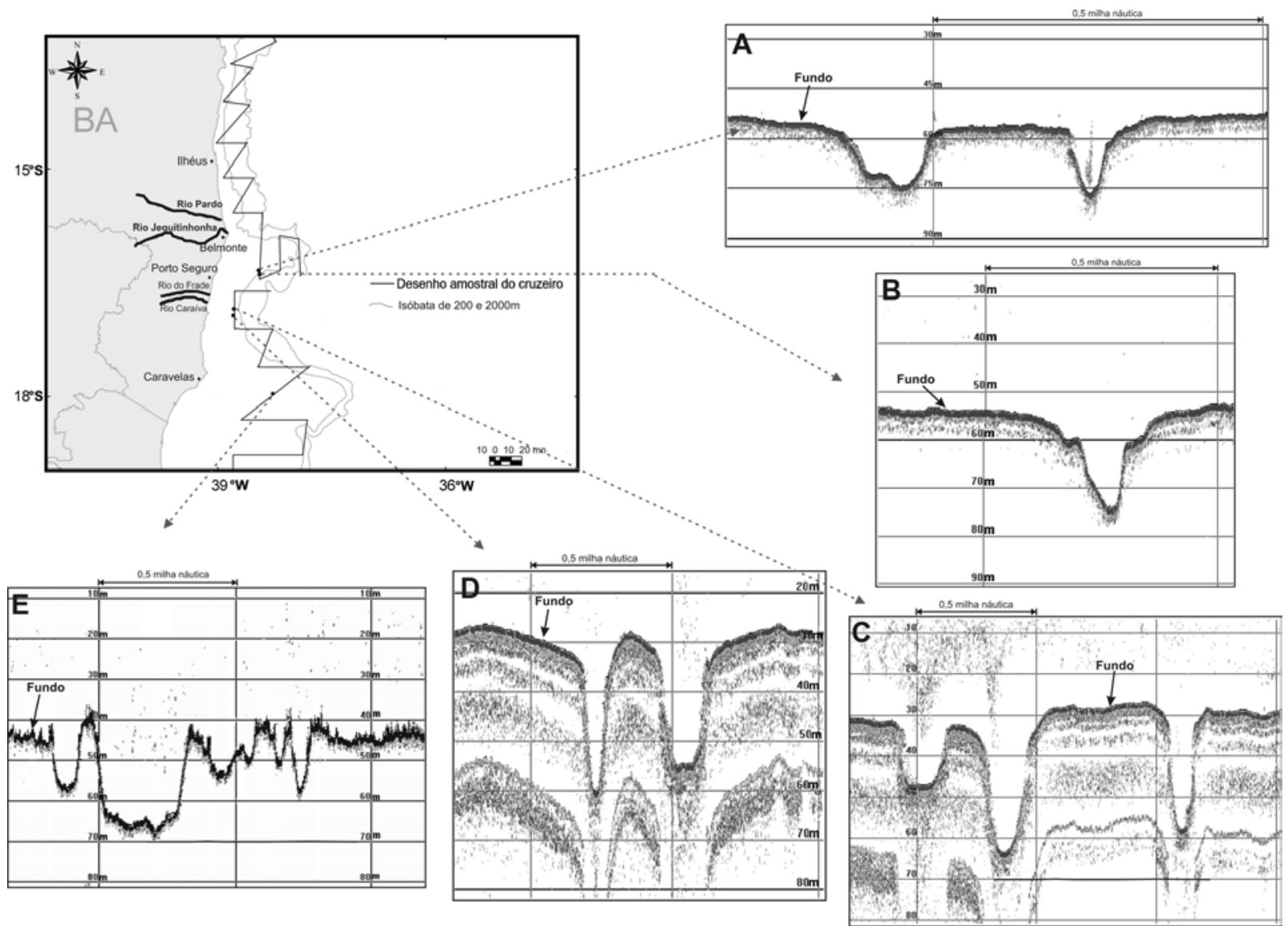

Figura 17 - Exemplos de ecogramas com presença de canais encontrados na costa da Bahia.

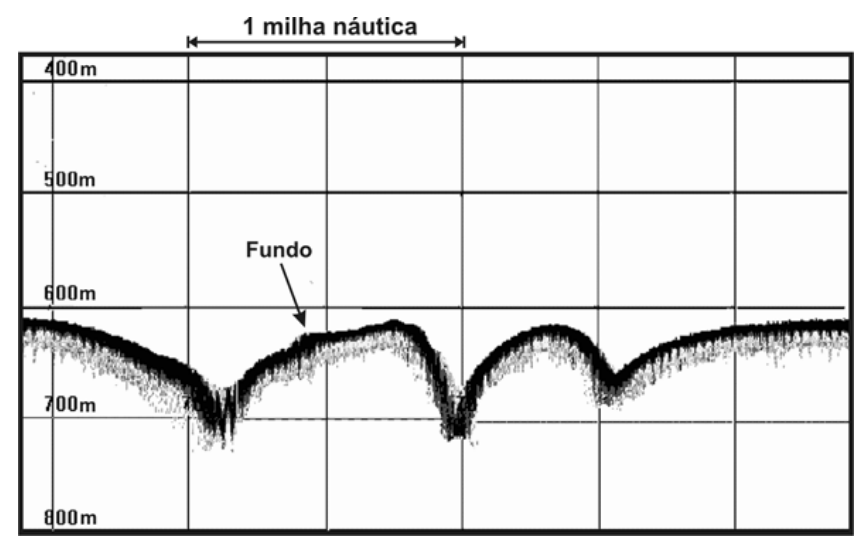

Figura 18 - Ecograma de fundo com presença de pockmarcks.

principalmente sobre a plataforma continental, onde o número de pulsos por unidade de tempo é superior em relação a áreas profundas. A identificação destas feições deverá ser de utilidade nas áreas biológica, geológica e ambiental, respectivamente gerando a caracterização de substratos, detalhando a morfologia do leito oceânico em termos de micro, meso e macro escalas e como informação auxiliar em processos de licenciamento ambiental.

Este trabalho pode ser de grande valia como auxiliar em trabalhos de mapeamento de recursos minerais marinhos na costa do Brasil. Sua contribuição na avaliação do potencial mineral de 
determinadas áreas se dá, diretamente através de informações sobre a distribuição superficial do sedimento correlacionado com a refletividade do fundo, e indiretamente através do mapeamento de feições e estruturas geológicas que favorecem a concentração de bens minerais de interesse. Além disso, as informações podem ser úteis na determinação dos pontos de amostragem e na escolha do tipo de amostrador, em trabalhos que venham a ser desenvolvidos. Cabe salientar que, em grande parte das áreas prospectadas não havia perfis acústicos disponíveis, particularmente nas regiões central e nordeste.

Grande parte dos dados utilizados neste trabalho localiza-se em áreas de interesse da indústria do petróleo. Portanto, o maior detalhamento das feições presentes nesta região pode contribuir para o conhecimento necessário na realização de várias operações indispensáveis da exploração de petróleo como, por exemplo, a colocação de dutos submarinos.

A disponibilização de todo o trabalho em um Sistema de Informações Geográficas permite o acesso rápido dos dados, além de possibilitar o cruzamento de informações para melhor interpretação dos resultados.

0 SIG foi adaptado ao ArcGis 9.1 que permite maior interatividade, além de suportar maior volume de dados, e as imagens de ecogramas, assim como perfis batimétricos e ecoperfis de refletividade, estão disponibilizadas para consulta pública no site http://www.prh27.log.furg.br.

\section{AGRADECIMENTOS}

A Agência Nacional do Petróleo, Gás Natural e Biocombustíveis/Programa de Recursos Humanos PRH 27; Comandante Homero Poujeaux Alvariza e tripulação do Navio Oceanográfico Atlântico Sul; Prof. Dr. Lauro Calliari (FURG/Laboratório de Oceanografia Geológica); Prof. Maria Isabel Machado (FURG/PRH 27) e à toda equipe do Laboratório de Tecnologia Pesqueira e Hidroacústica da FURG.

\section{REFERÊNCIAS}

COLLINS W, GREGORY R \& ANDERSON J. 1996. A Digital Approach to Seabed Classification. Sea Technology, 37(8): 83-87.

COMMITTEE ON ECOSYSTEM EFFECTS OF FISHING. 2002. Phase 1: Effects of Trawling and Dredging on Seafloor Habitat. Ocean Studies Board. Division on Earth and Life Studies. National Research Council. National Academy of Science. 126 pp. Disponivel em: <http:// www.nap.edu>. Acesso em: 31 ago. 2004.
COUTINHO PNC. 1996. Levantamento do estado da arte da pesquisa dos recursos vivos marinhos do Brasil - Oceanografia Geológica. Programa REVIZEE. 97pp.

DIAS GTM, EL ROBRINI M, FREIRE GSF \& FIGUEIREDO Jr AG. 2004. Cartas de Sedimento de Fundo. Áreas da Oceanografia Geológica (Sul, Central, Nordeste e Norte) - Programa de Avaliação do Potencial Sustentável dos recursos vivos na Zona Econômica Exclusiva. REVIZEE. CD-ROM de Cartas Sedimentológicas. Disponível em: $<$ http://www.mma.gov.br/ port/sqa/projeto/revizee>.

FRANÇA AMC. 1979. Geomorfologia da margem continental leste brasileira e das bacias oceânica adjacentes. In: CHAVES HAF (Ed.). Geomorfologia da margem continental brasileira e das áreas oceânicas adjacentes. Série Projeto REMAC, 7: 89-114. PETROBRAS, DNPM, CPRM, DHN, CNPq.

FIGUEIREDO Jr AG \& MADUREIRA LSP. 2004. Topografia, composição, refletividade do substrato marinho e identificação de províncias sedimentares na Região Sudeste-Sul do Brasil. Série Documentos Técnicos do Programa REVIZEE Score-Sul - São Paulo, Instituto oceanográfico USP. 64pp.

GERLOTTO F. 1996. Gregariousness and school behaviour of pelagic fish: impact of the acoustics evaluation and fisheries. Proceedings of Acoustics Seminar Akustikan 2. p. 233-251.

GUNDLACH ER \& HAYES MO. 1978. Vulnerability of coastal environments to oil spill impacts. Mar. Tech. Soc. J., 2(4): 18-27.

LEÃO ZMAN. 1999. Abrolhos-O Complexo recifal mais extenso do Oceano Atlântico Sul. Sítios Geológicos e Paleontológicos do Brasil. 090. Disponível em: <http://www.unb.br/ig/sigep/sitio090.htm>. Acesso em: 10 ago. 2004

MacLENNAN DN \& SIMMONDS EJ. 1992. Fisheries Acoustic. Chapman \& Hall. Fish. Fish. Ser., 5: 325 pp.

SOUZA JM de. 1999. Mar territorial, zona econômica exclusiva ou plataforma continental? Rev. Bras. Geof., 17(1): 79-82.

SUMIDA PYG, YOSHINAGA MY, MADUREIRA LAS \& HOVLANND M. 2004. Seabed pockmarks associated with deepwater corals off SE. Brazilian continental slope, Santos Basin. Mar. Geol., 207: 159-167.

TEGOWSKI J. 2005. Acoustical classification of the bottom sediments in the southern Baltic Sea. Quatern. Int., 130(1): 153-161.

ZEMBRUSCKI SG. 1979. Geomorfologia da Margem Continental Sul Brasileira e das Bacias Oceânicas Adjacentes. In: CHAVES HAF (Ed.). Geomorfologia da margem continental brasileira e das áreas oceânicas adjacentes. Série Projeto REMAC, 7: 129-177. PETROBRAS, DNPM, CPRM, DHN, CNPq. 


\section{NOTAS SOBRE OS AUTORES}

Caroline Vieira Cooke. Possui graduação em Oceanologia pela Fundação Universidade Federal do Rio Grande (2005). Tem experiência na área de Oceanografia, com ênfase em Oceanografia Geológica, Biológica e Hidroacústica aplicada. Atualmente é bolsista de mestrado do Programa de Pós-graduação em Oceanografia Biológica da Fundação Universidade Federal do Rio Grande e atua juntamente ao Laboratório de Tecnologia Pesqueira e Hidroacústica.

Lauro Antonio Saint Pastous Madureira. Possui graduação em Oceanologia pela Fundação Universidade Federal do Rio Grande (1980), onde é professor adjunto do Departamento de Oceanografia desde 1993, atuando nos cursos de Graduação em Oceanologia e Pós-graduação em Oceanografia Biológica. Obteve o grau de doutor na University of Cambridge em 1992, tendo trabalhado na Marine Life Sciences Division of the British Antarctic Survey. Participou das fases iniciais do Programa Antártico Brasileiro, integrando as Expedições I, II, III e V. No Programa REVIZEE coordenou e executou as atividades de Prospecção de Recursos Pelágicos com metodologia hidroacústica, mapeando as plataformas, talude e região oceânica adjacente entre a divisa do Brasil e Uruguai até o limite entre Ceará e Piauí, incluindo ilhas oceânicas.

Gilberto Henrique Griep. Possui graduação em Oceanologia pela Fundação Universidade Federal do Rio Grande (1977) e especialização em Administração Universitária pela Fundação Universidade Federal do Rio Grande (1995), onde atualmente é Professor Adjunto. Tem experiência na área de Geociências, com ênfase em Geofísica.

Marcelo Peres de Pinho. Possui graduação em Engenharia de Computação pela Fundação Universidade Federal do Rio Grande (2002). Atualmente é aluno do Programa de Pós-graduação em Oceanografia Química, Física e Geológica pela Fundação Universidade Federal do Rio Grande e atua juntamente ao Laboratório de Tecnologia Pesqueira e Hidroacústica da FURG. Tem experiência na área de Ciência da Computação, com ênfase em Metodologia e Técnicas da Computação. 